\title{
Palinomorfos e associações de fácies da Formação Lagoa Azul (Grupo Ita- raré, Pennsilvaniano da Bacia do Paraná) no sudeste do Estado do Paraná, Brasil
}

\author{
Felipe KIPPER ${ }^{1}$, Paulo A. SOUZA² \& Fernando Farias VESELY ${ }^{3}$
}

1 Programa de Pós-graduação em Geologia, Universidade Federal do Paraná. Caixa Postal 19.001, CEP 81.531-980, Curitiba, PR, Brasil (felipekipper@uol.com.br).

2 Departamento de Paleontologia e Estratigrafia, Instituto de Geociências, Universidade Federal do Rio Grande do Sul. Av. Bento Gonçalves, 9500, CEP 91.540-000, Porto Alegre, RS, Brasil (paulo.alves.souza@ufrgs.br).

3 Departamento de Geologia, Universidade Federal do Paraná. Caixa Postal 19.001, CEP 81.531-980, Curitiba, PR, Brasil (vesely@ufpr.br).

Recebido em 02/2016. Aceito para publicação em 12/2016.

Versão online publicada em 08/05/2017 (www.pesquisasemgeociencias.ufrgs.br)

\begin{abstract}
Resumo - No sudeste do Estado do Paraná, o Grupo Itararé assenta-se por meio de discordância angular sobre o substrato pré-glacial, que é composto de unidades precambrianas a devonianas, cada vez mais velhas para o sudeste. Devido a esta configuração estratigráfica, tem-se interpretado que os estratos aflorantes na região de Porto Amazonas representam os níveis mais inferiores do Grupo Itararé, enquanto aqueles da região de Campo do Tenente, localizados mais ao sul da área, representam seções mais jovens. Este artigo apresenta o resultado da análise palinológica e faciológica realizada em sete afloramentos da porção basal do Grupo Itararé (Formação Lagoa Azul), nas regiões de Porto Amazonas, Lapa e Campo do Tenente, visando ao posicionamento palinoestratigráfico. Nove fácies sedimentares foram identificadas compondo, na maior parte, depósitos de transporte de massa e turbiditos, acumulados em ambiente marinho relativamente profundo sob influência glacial. Associações palinológicas foram registradas em todas as três regiões, incluindo escassos elementos indígenas, compreendendo esporos e grãos de pólen monossacados, com grau de preservação variado. As características palinológicas gerais das associações e a presença de determinadas espécies de esporos e grãos de pólen sugerem posicionamento na Zona Ahrensisporites cristatus, correspondente à porção inferior do Grupo Itararé (Formação Lagoa Azul), de idade pennsilvaniana (Neobashkiriano a Kasimoviano). Os resultados obtidos confirmam a ocorrência de estratos glaciais da parte inferior do Grupo Itararé na faixa de afloramentos. Além disso, demonstram a importância do estudo dos processos de retrabalhamento e ressedimentação de palinofósseis pré-pennsilvanianos.
\end{abstract}

Palavras-chave: Carbonífero, bioestratigrafia, "palinomorfos retrabalhados", Gondwana.

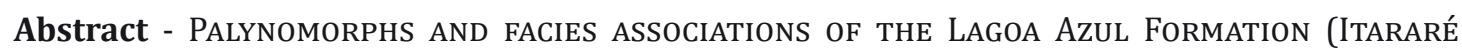
Group, PEnNSylvanian of the Paraná Basin), in Southeastern PARAná State, Brazil. In southeastern Paraná state, the Itararé Group rests through an angular unconformity over the preglacial substrate, composed of Precambrian to Devonian units which are increasingly older to the southeast. Because of this stratigraphic configuration, the outcrops of the Itararé Group in the Porto Amazonas region have been interpreted as representing its lowermost levels while those from the Campo do Tenente region, which are located more to the south, are considered to be younger. This paper presents the results of a palynological and facies analysis performed in seven outcrops from the lower portion of the Itararé Group (Lagoa Azul Formation) in the Porto Amazonas, Lapa and Campo do Tenente regions, aiming at the palynostratigraphic positioning. Nine sedimentary facies were identified, representing mostly mass-transport deposits and turbidites, deposited in a relatively deep marine environment under glacial influence. Palynological associations were recorded from all outcrops which are composed of scarce indigenous elements, comprising of spores and monosaccate pollen grains, with varied preservation degree. The general palynological features of the associations and the presence of certain species of spores and pollen grains suggest correlation to the Ahrensisporites cristatus Zone, which corresponds to the lower portion of the Itararé Group (Lagoa Azul Formation), of Pennsylvanian age (late Bashkirian to Kasimovian). The results corroborate the occurrence of glacial deposits of the lower Itararé Group in the outcrop belt. In addition, they demonstrate the importance of the study on processes of pre-Pennsylvanian palynofossils reworking and resedimentation.
\end{abstract}

Keywords: Carboniferous, biostratigraphy, "reworked palynomorphs", Gondwana. 


\section{Introdução}

O Grupo Itararé contém, na Bacia do Paraná, um dos registros mais extensos da glaciação do $\mathrm{Pa}$ leozoico superior do Gondwana, conhecida como Late Paleozoic Ice Age (LPIA). Inicialmente considerado como um longo e contínuo evento glacial, pontuado por breves fases interglaciais (Frakes \& Crowell, 1967, 1969; Eyles et al., 1993), novas evidências geocronológicas tem demonstrado que constitui vários eventos glaciais de curta duração (López Gamundí, 1997; Isbell et al., 2003a, 2003b; Limarino et al., 2006; Fielding et al., 2008).

Datações radiométricas são escassas no Grupo Itararé, restritas a determinados horizontes e ainda carentes de melhor resolução (Rocha-Campos et al., 2006), comprometendo um melhor estabelecimento da amplitude temporal de seus depósitos. Nesse contexto, o conteúdo fossilífero tem sido fortemente utilizado para a determinação de idades relativas, sobretudo os palinomorfos, em virtude de sua abundância e potencial de correlação local e entre outras bacias do Gondwana, conforme sintetizado em Azcuy et al. (2007).

Dados palinológicos advindos do Grupo Itararé são conhecidos em diversas partes da bacia, seja em subsuperfície ou afloramentos, permitindo a proposição de biozonas rastreáveis a longas distâncias (Daemon \& Quadros, 1970; Marques-Toigo, 1988, 1991; Souza \& Marques-Toigo, 2005; Souza, 2006). Contudo, a maioria de suas informações palinológicas é relativa a determinados setores da bacia, especialmente nos estados de São Paulo e Rio Grande do Sul.

No Estado do Paraná, excetuando-se os dados de subsuperfície (Daemon \& Quadros, 1970; Souza, 2006), há um número menos expressivo de associações palinológicas de localidades aflorantes. A análise estratigráfica realizada por Vesely et al. (2015) na região de Vila Velha e Porto Amazonas foi apoiada, em termos bioestratigráficos, pelo reconhecimento de palinozonas em certos níveis do Grupo Itararé, com o posicionamento estratigráfico e indicação de idades relativas.

0 presente trabalho é resultado do estudo de Kipper (2014), sobre o conteúdo palinológico de amostras provenientes de afloramentos do Grupo Itararé na região sudeste do Estado do Paraná, com discussões sobre o significado bioestratigráfico e interpretações sobre as associações de fácies descritas.

\section{2 Área, materiais e métodos}

Os afloramentos estudados estão localizados na borda leste da Bacia do Paraná, correspondente à região sudeste do Estado do Paraná (Fig. 1). As amostras foram coletadas em seções levantadas nos municípios de Porto Amazonas, Lapa e Campo do Tenente (Fig. 2A), posicionadas na Formação Lagoa Azul (França \& Potter, 1988), base do Grupo Itararé. 0 intervalo meso-superior dessa unidade é correlato à Formação Campo do Tenente, identificada por Schneider et al. (1974)nos estados do Paraná e Santa Catarina.

\subsection{Contexto estratigráfico}

Os depósitos paleozoicos da Bacia do Paraná são correspondentes a três supersequências de natureza transgressiva-regressiva denominadas por Milani (1997), em ordem estratigráfica ascendente: Rio Ivaí (Ordoviciano-Siluriano), Paraná (Devoniano) e Gondwana I (Permocarbonífero). 0 Grupo Itararé constitui a base da Supersequência Gondwana I, com espessura que ultrapassa 1.300 $\mathrm{m}$, distribuído de forma generalizada em todas as áreas da bacia, incluindo porções no Uruguai e na Argentina (Bacia Chacoparaná) Na figura 2B é apresentada uma coluna estratigráfica da $\mathrm{Su}$ persequência Gondwana I, com a litoestratigrafia do Grupo Itararé de acordo com França \& Potter (1988) e das unidades suprajacentes de acordo com Schneider et al. (1974).

Schneider et al. (1974) propuseram uma subdivisão litoestratigráfica tripartite para esta unidade nos estados do Paraná e Santa Catarina, compreendendo, da base para o topo, as formações Campo do Tenente, Mafra e Rio do Sul. Segundo Schneider et al. (1974), o Grupo Itararé é principalmente caracterizado por diamictitos, que refletem influências glaciais em diferentes ambientes deposicionais, além de arenitos, conglomerados, siltitos, argilitos, ritmitos, e subordinadas camadas de carvão. Por outro lado, com base em dados de subsuperfície, França \& Potter (1988) subdividiram o Grupo Itararé em três unidades litoestratigráficas, denominadas formações Lagoa Azul, Campo Mourão e Taciba, nomenclaturas adotadas nas cartas estratigráficas mais recentes da bacia (Milani et al., 2007; Holz et al., 2010). Estas unidades, definidas em subsuperfície, apresentam ciclos de sedimentação com afinamento dos grãos ascendente e que corresponderiam a mudanças climáticas cíclicas dentro do regime glacial, cada um ligado a uma subida do nível relativo do mar (França 


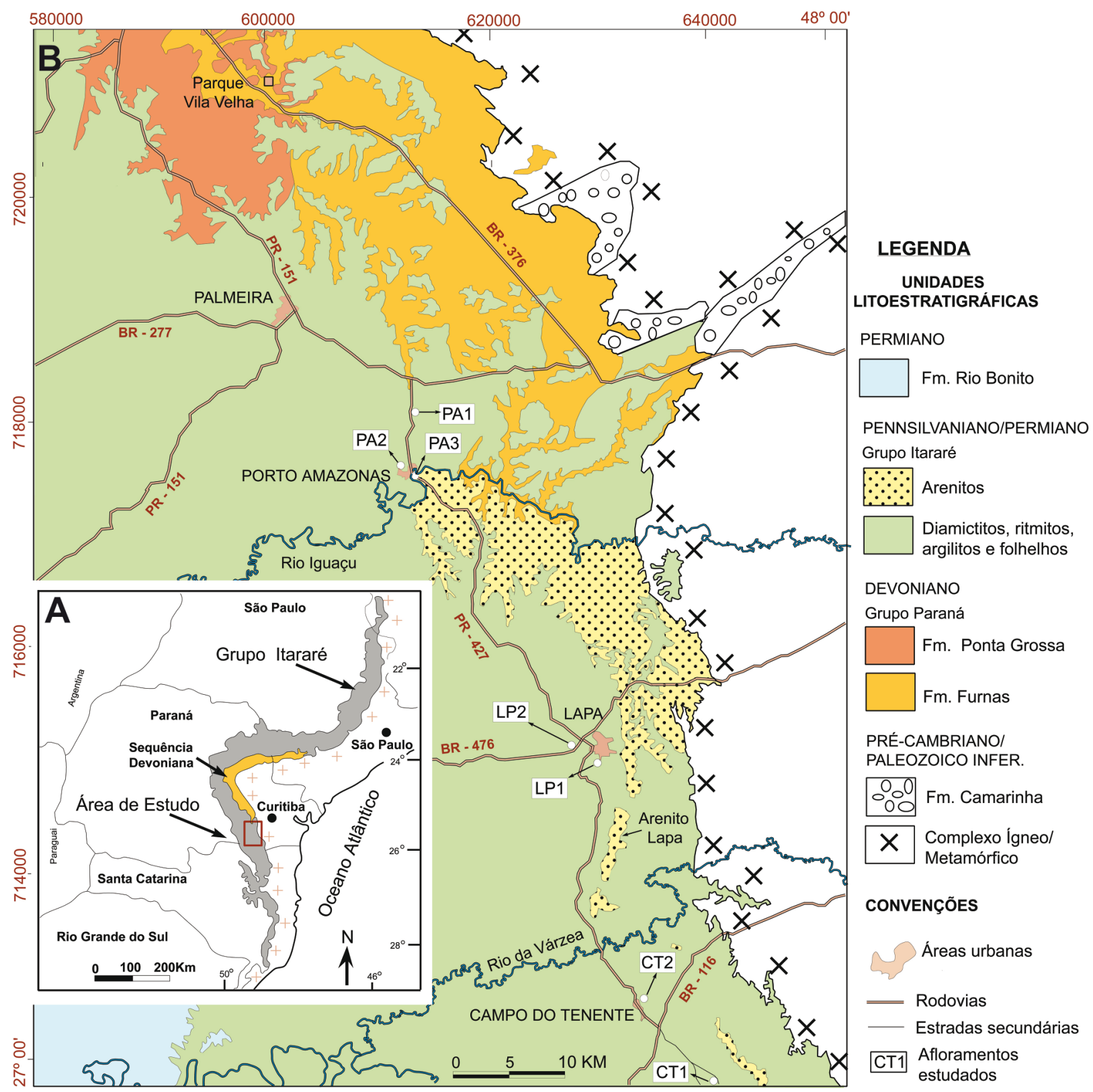

Figura 1. Localização e contexto geológico da área estudada. A) Faixa aflorante dos grupos Paraná e Itararé no flanco leste da Bacia do Paraná; B) Mapa geológico da área, com destaque aos afloramentos estudados (baseado em MINEROPAR, 2007).

Figure 1. Location and geological setting of the study area. A) Distribution of Devonian outcropping area of the Itararé Group in the eastearn flank of the Paraná Basin; B) Geological map of the area, highlighting the examined outcrops (based on MINEROPAR, 2007).

\section{\& Potter, 1988).}

A Formação Lagoa Azul possui 560 m de espessura máxima em subsuperfície (no Estado de São Paulo), com ocorrências mais comuns na ordem de 200 a 400 m (França \& Potter, 1988). Segundo Vesely et al. (2015), na zona de afloramentos nas regiões entre Vila Velha e Porto Amazonas (PR), a Formação Lagoa Azul possui uma espessura aproximada de $90 \mathrm{~m}$, sendo demarcada no seu limite superior por uma inconformidade angular capeada pelos arenitos avermelhados pós-glaciais "Vila Velha" descritos por Maack (1946). Segundo aqueles autores, abaixo desta inconformidade, são reconhecidas três unidades litoestratigráficas, nomeadas de 1 a 3, cuja associação de fácies registra a transição de um ambiente subglacial (Unidade 1) a glácio-marinho (Unidade 3).

Na área de estudo, o Grupo Itararé assenta-se por meio de uma discordância angular sobre o substrato pré-glacial, que é composto por unidades cada vez mais velhas para o sudeste (Fig. 2A). Ao sul do Rio Iguaçu, as unidades devonianas estão ausentes devido à erosão ocorrida no intervalo $\mathrm{Ne}$ odevoniano, e a Formação Lagoa Azul assenta-se 
diretamente sobre rochas ígneas e metamórficas do Pré-cambriano ao Eopaleozoico, pertencentes ao embasamento da Bacia do Paraná (Vesely \& Assine, 2014). 0 limite superior, com a Formação Campo Mourão, é caracterizado por uma discordância erosiva, como consequência da formação de vales incisos glaciais, com a deposição de espessos corpos de arenitos, tal como o "Arenito Lapa" (França et al., 1996).

De modo geral, o Grupo Itararé mostra tendência de onlap para o sul, de tal forma que os níveis inferiores afinam e desaparecem nesta dire- ção (Vesely et al., 2015). Devido a esse arcabouço estratigráfico regional, os estratos carboníferos assentados sobre o substrato têm sido interpretados como cada vez mais antigos para o norte (Porto Amazonas) e mais jovens para o sul da área estudada (Campo do Tenente) (Figura 2A).

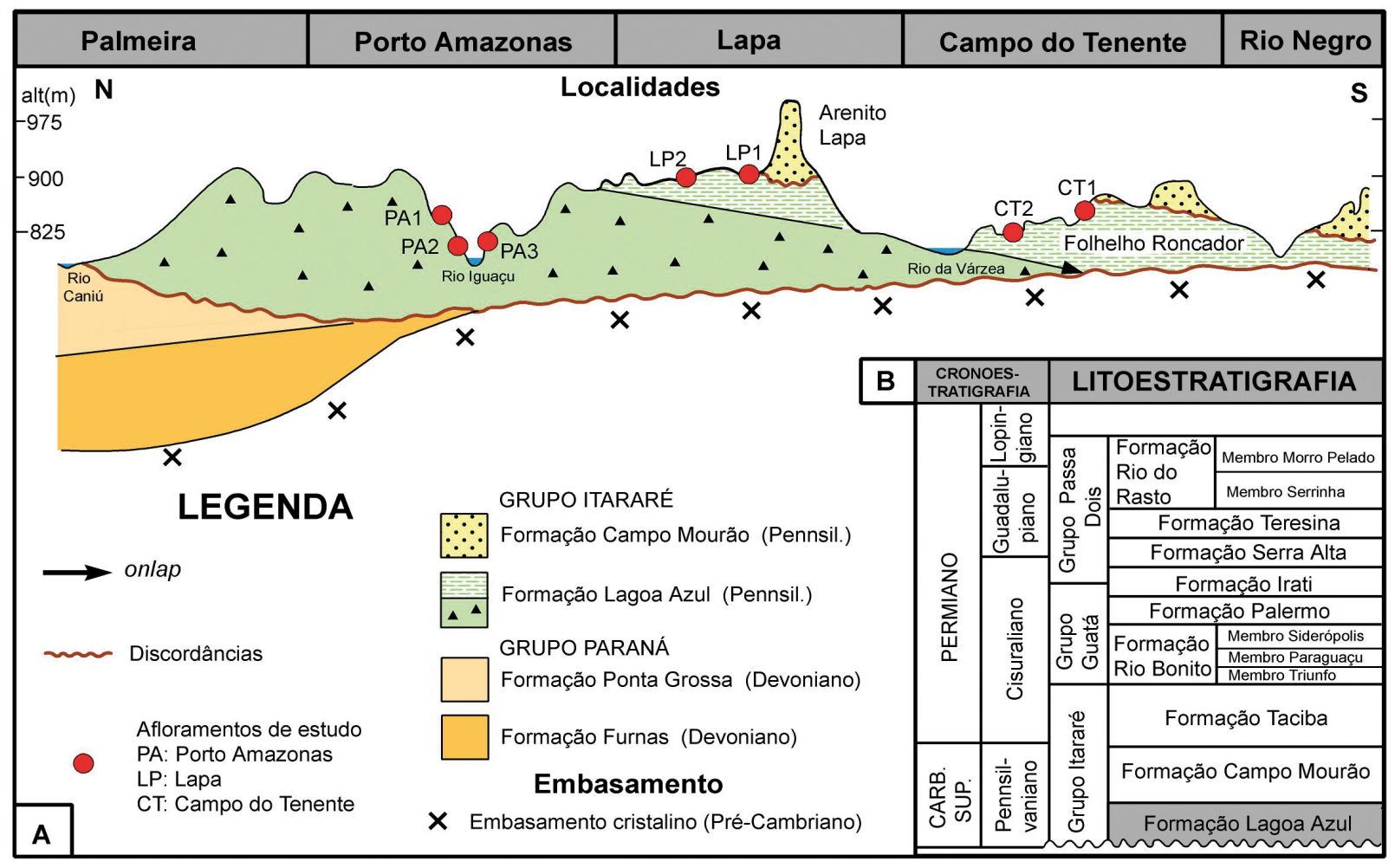

Figura 2. Estratigrafia da área estudada. A) Distribuição geral das unidades sedimentares e dos afloramentos (baseado em França et al., 1996; Vesely et al., 2015); B) Coluna estratigráfica da Supersequência Gondwana I (unidades do Grupo Itararé, conforme França \& Potter, 1988; unidades suprajacentes, Schneider et al., 1974; idades, Milani et al., 2007 e Holz et al., 2010 ). Figure 2. Stratigraphy of the study area. A) General distribution of the sedimentary units and outcrops (based on França et al., 1996; Vesely et al., 2015); B) Stratigraphic column of the Gondwana Supersequence (Itararé Group units according to França \& Potter, 1988; overlain units, Schneider et al., 1974; ages, Milani et al., 2007 and Holz et al., 2010).

\subsection{Palinoestratigrafia}

O zoneamento palinológico mais recente para o Pennsilvaniano e Permiano da Bacia do Paraná é composto por quatro zonas de intervalo (Souza \& Marques-Toigo, 2005; Souza, 2006), denominadas, da mais velha para a mais nova: Zona Ahrensisporites cristatus (ZAc), Zona Crucisaccites monoletus (ZCm), Zona Vittatina costabilis (ZVc) e Zona Lueckisporites virkkiae (ZLv). A três primeiras zonas ocorrem no Grupo Itararé. As biozonas ZAc e ZCm são relativas às porções basal e média do Grupo Itararé, respectivamente, distribuídas do estado do Paraná para norte da bacia, enquanto a ZVc é reconhecida de forma generalizada, no topo do Grupo Itararé e na Formação Rio Bonito, alcançando o sul da bacia no Brasil, com continuidade no Uruguai e Argentina (Souza et al., 2007).

De acordo com Souza (2006), a ZAc está materializada na Formação Lagoa Azul, sendo caracterizada pela presença de 11 táxons restritos, com domínio de esporos (principalmente relacionados às Lycophyta, Sphenophyta e Filicophyta) e grãos de pólen monossacados (Cordaitales/Coniferales). A ZCm possui, em geral, as mesmas características quantitativas que a sobrejacente ZAc, com pre- 
sença de táxons restritos (Crucisaccites monoletus e Scheuringipollenites maximus). Ambas zonas foram posicionadas no Pennsilvaniano, enquanto a $\mathrm{ZVc}$, que inclui a porção superior do Grupo Itararé e grande parte da Formação Rio Bonito, é considerada como Cisuraliana (Permiano Inferior), incluindo as primeiras ocorrências de táxons tipicamente permianos nesta porção do Gondwana (e.g., Converrucosisporites confluens, Vittatina costabilis, Illinites unicus).

\subsection{Levantamento estratigráfico e amostragem}

Foram investigados sete afloramentos da base até o topo da Formação Lagoa Azul, correspondentes a cortes de rodovias e pedreiras. Os afloramentos e amostras receberam códigos referentes às iniciais dos municípios de Porto Amazonas (PA1, PA2, PA3), Lapa (LP1, LP2) e Campo do Tenente (CT1 e CT2).

As 20 amostras coletadas em diferentes níveis estratigráficos foram submetidas ao processamento palinológico no Laboratório de Palinologia Marleni Marques Toigo do Instituto de Geociências da Universidade Federal do Rio Grande do Sul (LPMMT/IG/UFRGS). 0 tratamento empregado para a separação do resíduo palinológico é conforme descrito por Quadros \& Melo (1987), com modificações. 0 método consiste na trituração da rocha em fragmentos de 1 a $5 \mathrm{~mm}$ e no ataque com ácido clorídrico e fluorídrico para dissolução de materiais carbonáticos e minerais silicáticos, respectivamente. A separação da fração para estudo é feita por peneiramento em malhas de 25 e $250 \mu \mathrm{m}$, de modo a concentrar o resíduo palinológico para posterior montagem de lâminas. Para cada amostra foram confeccionadas duas lâminas, codificadas sob prefixo "MP-P" (7688-7689, 8786-8795, 8922-8925, 9239-9258, 9699-9710), depositadas na palinoteca do laboratório citado (Museu de Paleontologia do Departamento de Paleontologia e Estratigrafia do IG/UFRGS).

\section{Resultados}

\subsection{Descrição e interpretação das fácies}

Foram individualizadas nove fácies principais nos sete afloramentos (Fig. 3), agrupadas de acordo com a granulação e a estrutura sedimentar, em um esquema similar àqueles propostos por Miall (1978, 1996) e Eyles et al. (1985). As primeiras letras maiúsculas referem-se ao tipo litológico - S: Arenito; D: Diamictito; F: Folhelho; R: Ritmito - em ordem de dominância, e as últimas letras minúsculas indicam a estrutura sedimentar ou feição principal. A interpretação das fácies sedimentares foi realizada com base nos trabalhos de Suss et al. (2014) e Vesely et al. (2015), realizados na mesma área de estudo. No quadro 1 são apresentadas as descrições das fácies e suas respectivas interpretações, enquanto na figura 4 constam imagens dos afloramentos com detalhamento das fácies.

\subsection{Palinologia}

Palinomorfos indígenas foram registrados em quantidade e estado de preservação variável em 15 das 20 amostras analisadas. Esses elementos estão representados por associações de miósporos pouco abundantes e diversificadas, incluindo nove espécies de esporos, nove de grãos de pólen monossacados, táxons com nomenclatura aberta atribuídos a três gêneros de grãos de pólen monossacados (Cannanoropollis spp., Potonieisporites spp. e Caheniasaccites spp.), além de diversos grãos de pólen indeterminados.

Em algumas das amostras, palinomorfos retrabalhados comumente encontrados em seções do Devoniano são muito comuns, perfazendo a maioria dos táxons reconhecidos. Estes elementos, de preservação variável, compreendem esporos, acritarcos, algas clorófitas (prasinofíceas), escolecodontes e quitinozoários. A distribuição estratigráfica dos táxons considerados indígenas e retrabalhados é apresentada no quadro 2; fotomicrografias de espécimes selecionados constituem a figura 5.

\section{Discussão dos resultados}

\subsection{Afloramentos da região de Porto Amazonas}

\subsubsection{Análise das fácies sedimentares}

Os afloramentos estudados na região de Porto Amazonas (PA1, PA2 e PA3) estão posicionados a cerca de $70 \mathrm{~m}$ acima da base da Formação Lagoa Azul, inseridos dentro do intervalo estratigráfico denominado de "Unidade 3" por Vesely et al. (2015). Estes depósitos são constituídos por diamictitos, com matriz lamosa, homogêneos a estratificados (Dmm-d, Dms), contendo clastos dispersos de composição e tamanhos variados $(1-20 \mathrm{~cm})$ e feições de deformação plástica (Fig. 4E). Sucedendo este intervalo basal, ocorrem ritmitos (Fig. 4A) tanto com predominância de folhelho (RFS) 
Quadro 1. Descrição das fácies sedimentares com seus respectivos códigos e interpretação sobre os processos geradores. Chart 1. Sedimentary facies with respective codes and interpretation of the formative processes.

\begin{tabular}{|c|c|}
\hline Descrição & Interpretação \\
\hline \multicolumn{2}{|l|}{ Diamictito de matriz lamosa e maciço ( Dmm) } \\
\hline $\begin{array}{l}\text { Diamictito de matriz síltico-argilosa, a qual sustenta clastos de } \\
\text { diferentes composições (gnaisse, granito, xisto), arredondados a } \\
\text { subangulosos e de dimensões milimétricas a centimétricas (até } 10 \mathrm{~cm} \\
\text { de diâmetro), sem orientação preferencial. }\end{array}$ & $\begin{array}{l}\text { Sedimentação por decantação de uma } \\
\text { pluma de sedimentos finos, em condições } \\
\text { de baixa energia e abaixo da ação de ondas } \\
\text { e/ou fluxo gravitacional coesivo. } \\
\text { Clastos maiores indicam influência de gelo } \\
\text { flutuante e/ou transporte em suspensão } \\
\text { devido à coesão da matriz. }\end{array}$ \\
\hline \multicolumn{2}{|c|}{$\begin{array}{l}\text { Diamictito de matriz lamosa com feições de deformação sin-deposicional (Dmm-d) e planos de cisalhamento } \\
\text { (Dmm-s) }\end{array}$} \\
\hline $\begin{array}{l}\text { Diamictito de coloração acinzentada, apresentando matriz } \\
\text { predominantemente síltico-argilosa, sustentando clastos de diferentes } \\
\text { composições e dimensões, além de blocos de arenitos, de } 1 \text { a } 5 \mathrm{~m} \\
\text { (Dmm-d). Ocorrência marcante de feições de deformação como dobras, } \\
\text { superfícies de cisalhamento anastomosadas e diques clásticos de } \\
\text { arenitos, podendo apresentar foliação e/ou planos de cisalhamento } \\
\text { (fácies Dmm-s). }\end{array}$ & $\begin{array}{l}\text { Produto de ressedimentação, mediante } \\
\text { fluxo gravitacional de massa. }\end{array}$ \\
\hline \multicolumn{2}{|l|}{ Diamictitos estratificados (Dms) } \\
\hline $\begin{array}{l}\text { Diamictitos de matriz síltico-argilosa, com coloração acinzentada a } \\
\text { marrom quando alterado, apresentando nabase, camadastabulares com } \\
\text { grande quantidade de clastos, com tamanhos variando de milímetros } \\
\text { até } 15 \mathrm{~cm} \text { e composição variada (quartzo, argila, arenitos, granitos, } \\
\text { gnaisses, vulcânicas básicas); no topo, apresentam estratificação } \\
\text { incipiente, com níveis de clastos alinhados, alguns deformando a } \\
\text { laminação (dropstones). }\end{array}$ & $\begin{array}{l}\text { Origem subaquosa, mas produzida por } \\
\text { diversos processos, tais como decantação } \\
\text { de finos acompanhada de queda abundante } \\
\text { de clastos de icebergs, correntes de fundo e } \\
\text { ressedimentação. }\end{array}$ \\
\hline \multicolumn{2}{|l|}{ Arenito médio com gradação normal e intraclastos de argila (Sg-i) } \\
\hline $\begin{array}{l}\text { Arenito de coloração amarelada e granulação média, disposto em } \\
\text { camadas métricas ( } 2 \text { a } 5 \mathrm{~m} \text { ), maciço ou com gradação normal no topo, } \\
\text { e geometria tabular a lenticular com intraclastos de argila; no contato } \\
\text { entre os estratos ocorrem níveis centimétricos ( } 5 \text { a } 30 \mathrm{~cm} \text { ) de folhelho } \\
(\mathrm{Fl}) \text {; na base das camadas ocorrem feições erosivas e marcas de carga } \\
\text { sobre as camadas inferiores de ritmitos e diamictitos. }\end{array}$ & $\begin{array}{l}\text { Fluxos gravitacionais de sedimentos, } \\
\text { na forma de correntes de turbidez de } \\
\text { alta densidade com erosão do substrato } \\
\text { (intraclastos de argila dispersos na matriz). }\end{array}$ \\
\hline \multicolumn{2}{|l|}{ Ritmitos Folhelho-Siltito (RFS) } \\
\hline $\begin{array}{l}\text { Ritmito caracterizado por camadas gradadas de siltito passando a } \\
\text { argilito, de espessuras variando de } 0,5 \text { a } 25 \mathrm{~cm} \text {, e limitadas por contatos } \\
\text { abruptos; podem ou não apresentar clastos caídos, geralmente com } \\
\text { dimensões centimétricas. }\end{array}$ & $\begin{array}{l}\text { Sedimentação por decantação de areia fina } \\
\text { a muito fina, silte e argila (correntes de } \\
\text { turbidez de baixa densidade). }\end{array}$ \\
\hline \multicolumn{2}{|c|}{ Ritmito Siltito-Folhelho (RSF) / Ritmito Siltito-Folhelho com ondulações (RSFo) } \\
\hline $\begin{array}{l}\text { Ritmitos com predominância de níveis de siltito em relação aos níveis } \\
\text { de folhelho, constituído por camadas tabulares, com ondulação suave } \\
\text { e espessura média de } 5 \mathrm{~cm} \text {, finamente laminados; por vezes, os níveis } \\
\text { de silte apresentam ripples (RSFo); localmente esta fácies apresenta } \\
\text { intercalada com camadas centimétricas a métricas de folhelho (Fl). }\end{array}$ & $\begin{array}{l}\text { Sedimentação decorrente de fluxo } \\
\text { gravitacional, durante os estágios finais } \\
\text { de desaceleração do fluxo, quando atuam } \\
\text { associados processos hidrodinâmicos } \\
\text { trativos (correntes de turbidez de baixa } \\
\text { densidade). }\end{array}$ \\
\hline \multicolumn{2}{|l|}{ Folhelho (FI) } \\
\hline $\begin{array}{l}\text { Folhelhos marrons, cinzas quando inalterados, dispostos em camadas } \\
\text { centimétricas a métricas ( } 5 \mathrm{~m} \text { ), com contatos de topo e base abruptos, } \\
\text { podendo ou não apresentar clastos caídos. }\end{array}$ & $\begin{array}{l}\text { Produto de decantação lenta de argila } \\
\text { associada com queda de clastos de gelo } \\
\text { flutuante. }\end{array}$ \\
\hline
\end{tabular}

como de siltitos (RSF), alguns contendo marcas onduladas (RSFo). Estes ritmitos ocorrem na base ou intercalados a camadas de arenitos maciços ou com gradação normal no topo (Sg-i), tabulares a amalgamados, de granulação fina a grossa, com marcas de carga e clastos de argilitos na base.

Camadas espessas de arenitos (Sg-i) com clastos de folhelho arrancados do substrato e estrutu- ras de carga na base constituem os depósitos de correntes de turbidez de alta densidade. 0 caráter erosivo do fluxo indicado pelos clastos de folhelho e camadas amalgamadas pode indicar algum grau de confinamento para os sistemas de turbiditos na forma de canais ou ponds (Suss et al., 2014; Vesely et al., 2015). Os ritmitos com clastos (RFS, RSFo) são interpretados como camadas delgadas de tur- 


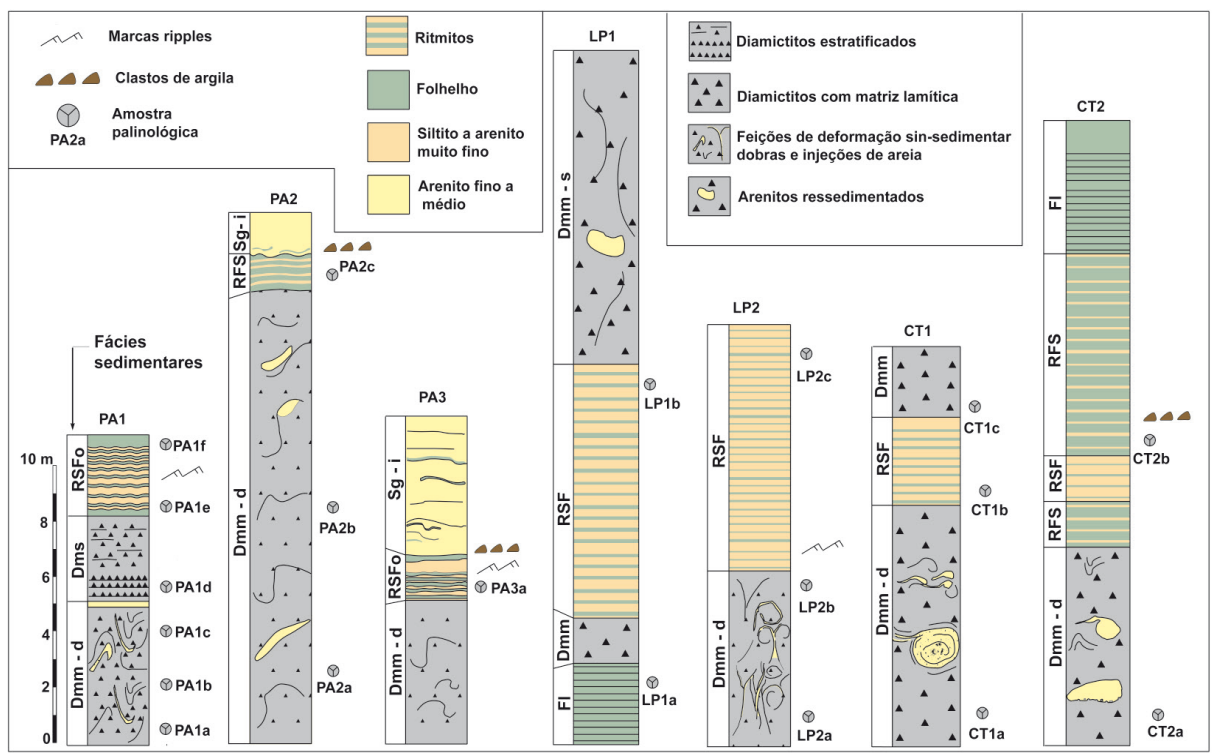

Figura 3. Perfis estratigráficos verticais dos afloramentos, com indicação das fácies sedimentares e níveis da amostragem palinológica (PA1 a PA3: Afloramentos da região de Porto Amazonas; LP1 e LP2: Afloramentos da região da Lapa; CT1 e CT2: Afloramentos da região de Campo do Tenente).

Figure 3. Vertical logs of the examined outcrops, with indication of the sedimentary facies and the levels of the palynological sampling (PA1 to PA3: Outcrops of the Porto Amazonas region; LP1 and LP2: Oucrops of the Lapa region; CT1 and CT2: Outcrops of the Campo do Tenente region).
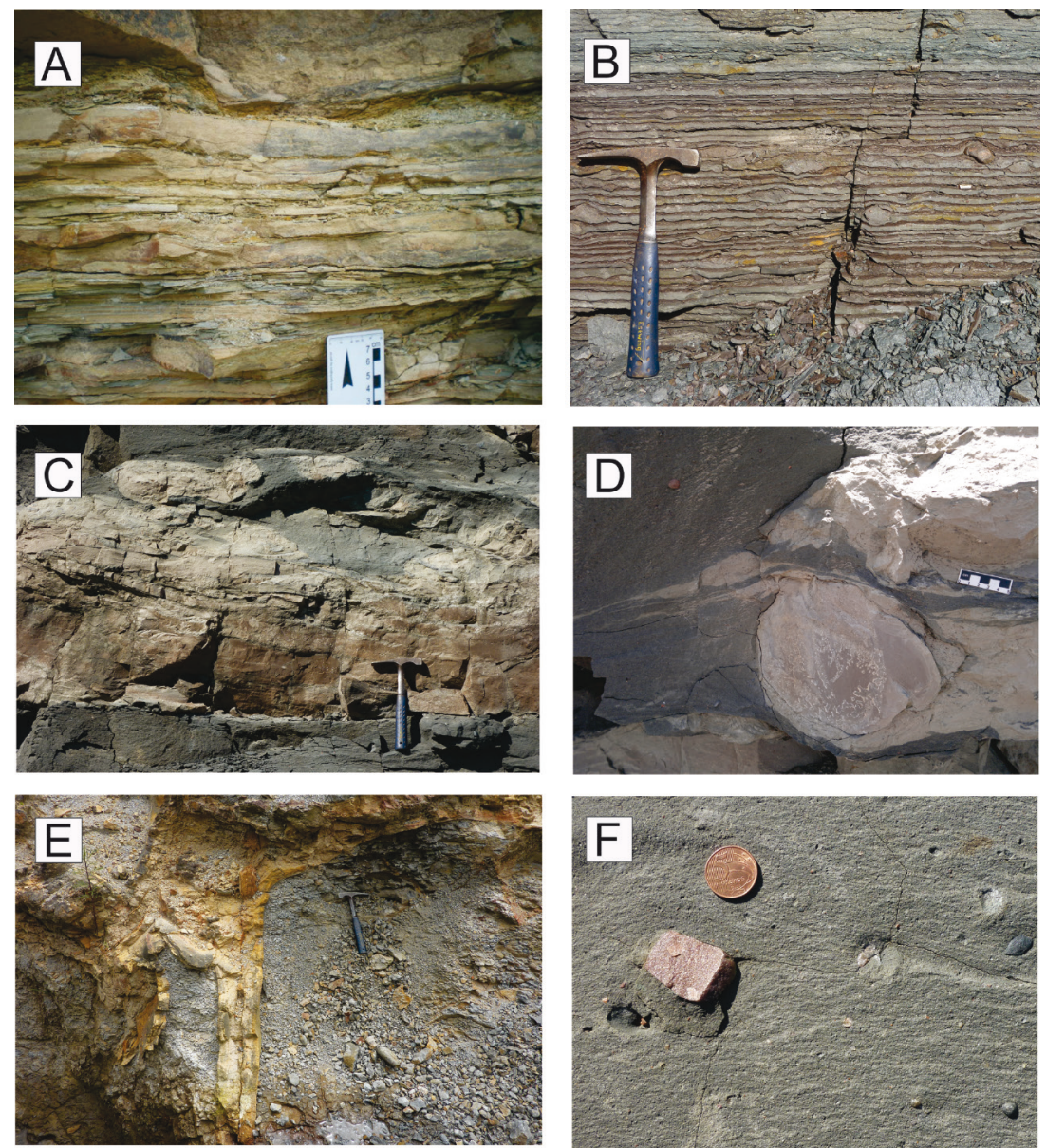

Figura 4. Afloramentos e fácies sedimentares da Formação Lagoa Azul. A) Ritmitos (RSFo) no afloramento PA3; B) Fácies de ritmitos (RFS) com clastos de argila no afloramento CT2; C) Depósitos de transporte de massa (DTM) com blocos de arenitos ressedimentados; D) Feições de deformação penecontemporâneas no afloramento CT1 (Dmm-d); E) Diamictitos (Dmm-d) com injeções de areia no afloramento PA1; F) Matriz lamosa típica com clastos dispersos (fácies Dmm-d)

Figure 4. Examples of facies of the Lagoa Azul Formation. A) Rhythmites (RSFo) in outcrop PA3; B) Thin-bedded rhythmite with dropstones (RFS) in outcrop CT2; C) Resedimented sandstone blocks in facies Dmm-d; D) Soft-sediment deformational features in outcrop CT1 (Dmm-d); E) Sand injections in Dmm-d, outcrop PA1; F) Typical muddy matrix with sparse centimetric clasts in Dmm$-d$. 


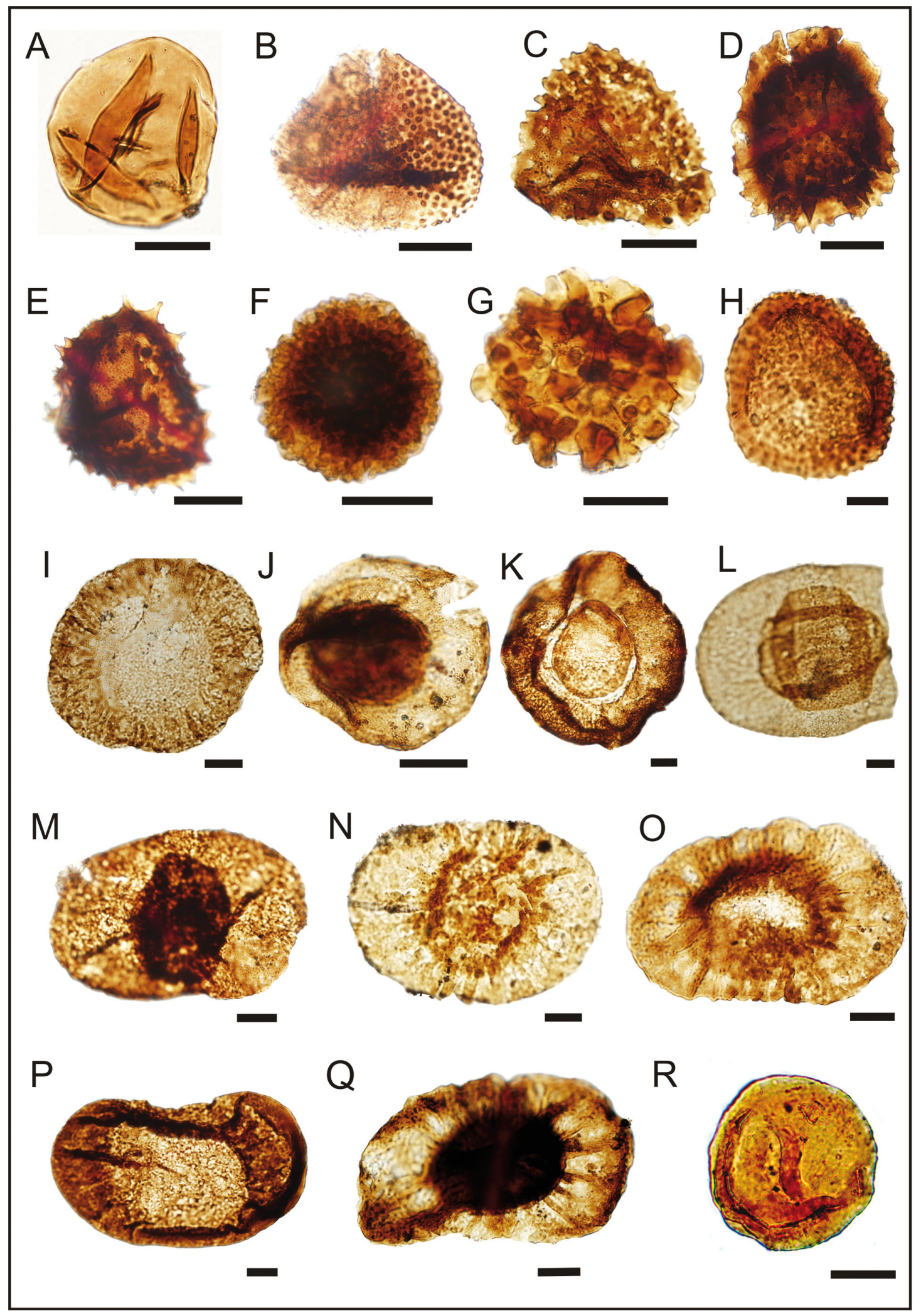

Figura 5. Fotomicrografias de palinomorfos selecionados da Formação Lagoa Azul. A) Calamospora sp. (amostra PA1b, lâmina MP-P 8790, coordenada England Finder T52); B) Granulatisporites micronodosus (CT1c, MP-P 9257, R46); C) Cristatisporites lestai (CT2b, MP-P 9256, L44); D) Cristatisporites scabiosus (CT1a, MP-P 9250, M53); E) Cristatisporites inconstans (LP1a, MP-P 9240, M47); F) Spacmanites sp. (LP1b, MP-P 9241, P26); G) Raistrickia densa (PA3a, MP-P 9705, 038); H) Cristatisporites menendezii (PA2c, MP-P 9704, T53); I) Cannanoropolis janakii (CT1c, MP-P 9257, F43); J) Densipollenites sp. (LP1b, MP-P 9241, G35); K) Circumplicatipollis stigmatus (CT2a, MP-P 9253, T41); L) Potoniesporites neglectus (CT2b, MP-P 9255, Q39); M) Potoniesporites barrelis (LP1a, MP-P 9239, K50); N) Caheniassaccites verrucosus (PA1c, MP-P 8926, F43); 0) Caheniassaccites flavatus (CT1c, MP-P 9258, S40); P) Caheniassaccites elongatus (CT1c, MP-P 9257, M37); Q) Costatascyclus crenatus (CT1a, MP-P 9250, J45); R) Tasmanites sp. (CT1c, MP-P 9258, R37). (Escala $=20 \mu \mathrm{m}$.)

Figure 5. Photomicrographs of selected palynomorphs from the Lagoa Azul Formation. A-R) (sample, slide and England Finder coordinate). (Scale $=20 \mu \mathrm{m}$.) 
biditos resultado de correntes de turbidez de baixa densidade combinados com a queda de detritos de gelo flutuante (Vesely et al., 2015), sendo os diamictitos de matriz lamosa (Fig.4F), muito comuns nesta unidade, resultado da homogeneização progressiva da areia, lama e cascalho derivadas de áreas mais proximais próximo à margem de bacia.

Segundo Vesely et al. (2015), a Unidade 3 pode ser interpretada como um complexo de talude glácio-marinho com influência glacial indireta e dominado por diferentes categorias de fluxos de massa.

\subsubsection{Palinologia e bioestratigrafia}

Nos depósitos mais basais estudados, da região de Porto Amazonas (Afloramentos PA1, PA2, PA3), raros grãos de pólen monossacados foram registrados (Cannanoropolis, Caheniassacites e Potoniesporites), em conjunto com uma grande abundância e diversidade de espécies retrabalhadas pré-pennsilvanianas (principalmente do

Quadro 2. Distribuição estratigráfica dos palinomorfos dos afloramentos das regiões de Porto Amazonas (PA1, PA2 e PA3), Lapa (LP1 e LP2) e Campo do Tenente (CT1 e CT2).

Chart 2. Stratigraphical distribution of the palynomorphs from the outcrops of Porto Amazonas (PA1, PA2 and PA3), Lapa (LP1ande LP2) and Campo do Tenente (CT1 and CT2) regions.

\begin{tabular}{|c|c|c|c|c|c|c|c|c|c|c|c|c|c|c|c|c|c|c|c|c|}
\hline \multirow{4}{*}{ CONTEÚDO PALINOLÓGICO } & \multicolumn{20}{|c|}{ NÍVEIS AMOSTRADOS POR AFLORAMENTO } \\
\hline & \multicolumn{10}{|c|}{ Porto Amazonas } & \multicolumn{5}{|c|}{ Lapa } & \multicolumn{5}{|c|}{ Campo do Tenente } \\
\hline & \multicolumn{6}{|c|}{ PA1 } & \multicolumn{3}{|c|}{ PA2 } & \multirow{2}{*}{$\begin{array}{l}3 \\
\end{array}$} & \multicolumn{2}{|c|}{ LP1 } & \multicolumn{3}{|c|}{ LP2 } & \multicolumn{3}{|c|}{ CT1 } & \multicolumn{2}{|c|}{ СT2 } \\
\hline & $\mathrm{a}$ & $\mathrm{b}$ & $\mathrm{c}$ & $\mathrm{d}$ & $\mathrm{e}$ & $\mathrm{f}$ & $\mathrm{a}$ & $\mathrm{b}$ & $\mathrm{c}$ & & $\mathrm{a}$ & $\mathrm{b}$ & $\mathrm{a}$ & $\mathrm{b}$ & $\mathrm{c}$ & $\mathrm{a}$ & $\mathrm{b}$ & $\mathrm{c}$ & $\mathrm{a}$ & $\mathrm{b}$ \\
\hline \multicolumn{21}{|l|}{ PALINOMORFOS ÍNDIGENAS } \\
\hline \multicolumn{21}{|l|}{ Esporos } \\
\hline Calamospora sp. & & $\mathrm{R}$ & & & & & & & & & & & & & & & & & & \\
\hline $\begin{array}{l}\text { Cristatisporites inconstans Archangelsky \& Gamerro } \\
1979\end{array}$ & & & & & & & & & & & $\mathrm{R}$ & & & & & & & & & \\
\hline Cristatisporites lestai Archangelsky \& Gamerro 1979 & & & & & & & & & & & & & & & & & & & & $\mathrm{R}$ \\
\hline Cristatisporites scabiosus Menéndez 1965 & & & & & & & & & & & & & & & & $\mathrm{R}$ & & & & \\
\hline $\begin{array}{l}\text { Densosporites annulatus (Loose) Smith \& Butterworth } \\
1967\end{array}$ & & & $\mathrm{R}$ & & & & & & & & $\mathrm{R}$ & & & & & & & & & \\
\hline $\begin{array}{l}\text { cf. Granulatisporites micronodosus Balme \& Hennelly } \\
1956\end{array}$ & & & & & & & & $\mathrm{R}$ & & & & & & & & $\mathrm{R}$ & & & & \\
\hline $\begin{array}{l}\text { Cristatisporites menendezii (Menéndez \& Azcuy) } \\
\text { Playford emend. Césari } 1985\end{array}$ & $\mathrm{R}$ & & & & & & & $\mathrm{R}$ & & & & $\mathrm{R}$ & & & & & & & & \\
\hline Raistrickia densa Menéndez 1965 & & & & & & & & & & $\mathrm{R}$ & & & & & & & & & & \\
\hline Spacmanites sp. & & & & & & & & & & & $\mathrm{R}$ & & & & & & & & & \\
\hline \multicolumn{21}{|l|}{ Grãos de pólen } \\
\hline Caheniasaccites elongatus Bose \& Kar 1966 & & & & & & & & & & & & & & & & & & $\mathrm{R}$ & & \\
\hline $\begin{array}{l}\text { Caheniasaccites flavatus (Bose \& Kar) Azcuy \& di Pasquo } \\
2000\end{array}$ & & & & & & & & & & & & & & & & & & $\mathrm{R}$ & & \\
\hline $\begin{array}{l}\text { Caheniasaccites verrucosus (González-Amicón) Gutiérrez } \\
1993\end{array}$ & & & & & $\mathrm{R}$ & & & & & & & & & & & & & & & \\
\hline Caheniasaccites spp. & & & & & $\mathrm{R}$ & & & & & & & $\mathrm{R}$ & & & & & & & & \\
\hline Cannanoropollis janakii Potonié \& Sah 1969 & & & & & $\mathrm{R}$ & & & & & & & $\mathrm{R}$ & & & & & & $\mathrm{R}$ & & \\
\hline Cannanoropollis spp. & & & & & & & & & & & $\mathrm{R}$ & & & & & & & & & \\
\hline $\begin{array}{l}\text { Circumplicatipollis stigmatus (Lele \& Karim) Ottone \& } \\
\text { Azcuy } 1988\end{array}$ & & & & & & & & & & & & & & & & & & $\mathrm{R}$ & & \\
\hline Costatacyclus crenatus (Felix \& Burbridge) Urban 1971 & & & & & & & & & & & & & & & & $\mathrm{R}$ & & & & \\
\hline Densipollenites sp. & & & & & & & & & & & & $\mathrm{R}$ & & & & $\mathrm{R}$ & & & & \\
\hline Potoniesporites barrelis Tiwari 1965 & & & & & & & & & & & $\mathrm{R}$ & & & & & & & & & \\
\hline Potoniesporites neglectus Potonié \& Lele 1961 & & & & & & & & & & & & & & & & & & & & $\mathrm{R}$ \\
\hline Potoniesporites spp. & & & $\mathrm{R}$ & & & & & & & & & & & & & & & & & \\
\hline Monossacados spp. & & & & & & & & & $\mathrm{R}$ & & $\mathrm{R}$ & $\mathrm{F}$ & & & & $\mathrm{R}$ & & $\mathrm{F}$ & & $\mathrm{F}$ \\
\hline \multicolumn{21}{|l|}{ Algas } \\
\hline Botryococcus braunii Kutzing 1849 & $\mathrm{R}$ & & $\mathrm{R}$ & & & $\mathrm{R}$ & & & & & & & & & & & $\mathrm{R}$ & & & \\
\hline Leiosphaeridia spp. & $\mathrm{R}$ & $\mathrm{F}$ & $\mathrm{A}$ & & $\mathrm{A}$ & $\mathrm{F}$ & $\mathrm{A}$ & $\mathrm{R}$ & $\mathrm{R}$ & $\mathrm{F}$ & & $\mathrm{A}$ & $\mathrm{A}$ & & $\mathrm{R}$ & $\mathrm{R}$ & $\mathrm{F}$ & $\mathrm{F}$ & $\mathrm{F}$ & \\
\hline Tasmanites spp. & $\mathrm{R}$ & $\mathrm{R}$ & $\mathrm{R}$ & & $\mathrm{F}$ & $\mathrm{R}$ & & & & $\mathrm{R}$ & $\mathrm{R}$ & $\mathrm{R}$ & & & & $\mathrm{R}$ & $\mathrm{R}$ & $\mathrm{R}$ & & $\mathrm{R}$ \\
\hline \multicolumn{21}{|l|}{ PALINOMORFOS RETRABALHADOS } \\
\hline \multicolumn{21}{|l|}{ Grãos de pólen } \\
\hline Prasinofíceas & $\mathrm{A}$ & $\mathrm{A}$ & $\mathrm{A}$ & & $\mathrm{A}$ & $\mathrm{A}$ & $\mathrm{A}$ & $\mathrm{F}$ & $\mathrm{F}$ & $\mathrm{F}$ & $\mathrm{R}$ & $\mathrm{R}$ & $\mathrm{R}$ & $\mathrm{R}$ & $\mathrm{R}$ & $\mathrm{R}$ & $\mathrm{R}$ & $\mathrm{R}$ & $\mathrm{R}$ & \\
\hline Acritarcos & $\mathrm{A}$ & $\mathrm{A}$ & A & & $\mathrm{A}$ & $\mathrm{A}$ & $\mathrm{A}$ & $\mathrm{A}$ & $\mathrm{A}$ & $\mathrm{F}$ & & $\mathrm{R}$ & $\mathrm{R}$ & & $\mathrm{R}$ & $\mathrm{R}$ & $\mathrm{R}$ & $\mathrm{R}$ & $\mathrm{R}$ & $\mathrm{R}$ \\
\hline Criptoesporos / Esporos & $\mathrm{F}$ & $\mathrm{F}$ & $\mathrm{A}$ & & $\mathrm{A}$ & $\mathrm{F}$ & $\mathrm{A}$ & $\mathrm{A}$ & $\mathrm{F}$ & $\mathrm{F}$ & $\mathrm{R}$ & $\mathrm{R}$ & $\mathrm{R}$ & & $\mathrm{R}$ & & $\mathrm{R}$ & $\mathrm{R}$ & $\mathrm{R}$ & \\
\hline Quitinozoários & $\mathrm{R}$ & $\mathrm{R}$ & & & & $\mathrm{R}$ & $\mathrm{R}$ & & & $\mathrm{R}$ & & $\mathrm{R}$ & & & & & $\mathrm{R}$ & & $\mathrm{R}$ & \\
\hline
\end{tabular}

Legenda: R - raro; F - frequente; A - abundante.

Devoniano). Esse conjunto inclui tanto elementos marinhos, como prasinofíceas dos gêneros Duvernaisphaera, Hemiruptia, Pterospermella e Maranhites e acritarcos, tais como dos gêneros Bimerga, Cordobesia, Evittia, Gorgonisphaeridium, Leiofusa, Michrystridium, Multiplicisphaeridium, Navifusa, Triangulina, Tunisphaeridium e Veryhachium, e elementos terrestres, como miósporos dos gêneros Emphanisporites, Dictyotriletes, Grandispora, Synosporites, Spelaeotriletes, Lophozonotriletes, Brochotriletes, Gneudasporas e Tetrahedraletes.
O predomínio de grãos de pólen monossacados de simetria radial e bilateral é característica das zonas Ahrensisporites cristatus e Crucisaccites monoletus (ZAc e ZCm) de Souza (2006), referentes às porções inferior e média do Grupo Itararé. Espécies de grãos de pólen teniados e poliplicados são ausentes. Embora grãos de pólen teniados possam ser registrados em quantidades subordinadas nas biozonas ZAc e ZCm, são comuns na suprajacente Zona Vittatina costabilis (ZVc).

Segundo Félix \& Souza (2008), a espécie de 
grão de pólen monossacado Caheniasaccites verrucosus (González-Amicón) Gutiérrez 1993, registrada no nível PA1 e na localidade de Porto Amazonas, é restrita às biozonas $\mathrm{ZAc}$ e ZCm. Contudo, considerando os táxons selecionados por Souza (2006), o registro de Cristatisporites menendezii nos afloramentos de Porto Amazonas permite posicionamento na ZAc, uma vez que se trata de espécie exclusiva desta zona. Tal atribuição bioestratigráfica, na base do Grupo Itararé, é também reforçada por alguns aspectos estratigráficos e palinológicos, além das características apontadas anteriormente, incluindo: (i) o posicionamento estratigráfico das seções, logo acima dos estratos devonianos das Formações Furnas e Ponta Grossa, (ii) presença de Raistrikia densa Menéndez 1965 no ponto PA3a e (iii) ausência de elementos típicos das biozonas suprajacentes, ZCm e ZVc.

A espécie de esporo Raistrikia densa foi descrita em estratos pennsilvanianos da Argentina, sendo comumente encontrada em associação com elementos típicos da ZAc, tais como Ahrensisporites cristatus Playford \& Powis 1979, Granulatisporites varigranifer Menéndez \& Azcuy 1971 e $F$. hortonensis (Playford) Azcuy 1975 (vide Azcuy, 1975a, 1975b; Souza, 2006). Embora algumas destas espécies possam ser também encontradas em zonas suprajacentes em território argentino (vide Césari \& Gutiérrez, 2000), na Bacia do Paraná, estes táxons ocorrem, em conjunto, de forma restrita na base do Grupo Itararé (ZAc), com idade relativa ao Pennsilvaniano.

\subsection{Afloramentos da região da Lapa e Campo do Tenente}

\subsubsection{Análise da fácies sedimentares}

Os afloramentos de Lapa (LP1 e LP2) e de Campo do Tenente (CT1 e CT2) correspondem à porção média a superior da Formação Lagoa Azul. A sucessão sedimentar deste intervalo é constituída por uma seção de ritmitos e folhelhos intercalada com depósitos de transporte de massa (DTM). Este intervalo pelítico é interpretado como uma superfície de afogamento marcada pela presença de um delgado horizonte de folhelhos denominados informalmente de "Folhelho Chocolate" por Maack (1946) ou Folhelho Roncador (França \& Potter, 1988). França et al. (1996) identificaram palinomorfos de idade westfaliana nos folhelhos da Formação Campo do Tenente (sensu Schneider et al., 1976), além de Tasmanites spp., que indicam condições marinhas. Vale ressaltar que a Forma- ção Campo do Tenente é equivalente à porção superior da Formação Lagoa Azul (Membro Tarabai) de França \& Potter (1988).

Os DTMs consistem de diamictitos dominados por matriz lamosa homogênea (Dmm) (Fig. 4F), com feições de deformação penecontemporânea e clastos extrabaciais (granito, gnaisse, xisto, etc.). No afloramento CT2, foi observada a presença de diamictitos (Dmm-d) sustentando blocos métricos a decamétricos de arenito de granulação fina a média, moderadamente selecionado, com estratificação cruzada dos tipos planar (Fig. 4C), sigmoidal e hummocky. Por vezes, estes blocos podem se apresentar rotacionados (Fig. 4D) e alongados horizontalmente.

Os ritmitos (RFS, RSF, RSFo) são compostos por camadas gradadas de arenito muito fino a lamito, com espessuras entre 5 a $40 \mathrm{~cm}$ e contatos abruptos entre si (Fig. 4B). Na base das camadas são observadas marcas de sola e estruturas de carga elípticas a alongadas. Os níveis mais síltico-arenosos podem apresentar ripples centimétricas.

As características dessa associação indicam deposição abaixo do nível de ação das ondas num contexto de talude ou sopé de talude influenciado por gelo flutuante. As feições observadas nos ritmitos, como gradação normal, ripples cavalgantes e marcas de sola associadas, são características dos turbiditos do tipo Bouma (1962). Segundo Suss et al. (2014), esses turbiditos ocorrem recobrindo ou margeando lateralmente os depósitos de transporte em massa.

\subsubsection{Palinologia e biostratigrafia}

Grãos de pólen monossacados (Cannanoropollis, Caheniasaccites, Circumplicatipollis, Costatascyclus, Crucisaccites, Densipollenites, Potonieisporites) são relativamente mais comuns nas associações referentes aos afloramentos localizados nas porções central e sul da área, em Lapa e Campo do Tenente. Nestes, ocorre drástica diminuição da participação de espécies retrabalhadas, com prasinofíceas (Maranhites, Hemiruptia, Duvernaisphaera), acritarcos (Veryhachium, Michrystridium, Tunisphaeridium, Triangulina, Bimerga, Cordobesia) e miósporos (Grandispora, Gneudaspora, Chelinospora, Retusotriletes).

Tal como na área de Porto Amazonas, a presença de Cristatisporites menendezii em Lapa permite posicionamento na ZAc. Nos afloramentos de Campo do Tenente, nenhum táxon registrado é diagnóstico em termos bioestratigráficos. De acordo com a revisão sobre os grãos de pólen monossacados realizada por Félix (2007) e Félix \& Souza 
(2008), Costatascyclus crenatus Felix \& Burbridge emend. Urban 1971 (ocorrente no nível CT1a do afloramento de Campo do Tenente) é restrita à ZAc. Contudo, há que se observar que esta mesma espécie ocorre também na Formação Aquidauana, no estado do Mato Grosso do Sul, em associação atribuída à Zona Crucisaccites monoletus (Souza et al., 2015), típica da Formação Campo Mourão (porção média do Grupo Itararé), o que requer melhor análise do zoneamento de Souza (2006) e do significado bioestratigráfico desta espécie.

Dois táxons inéditos para o intervalo Pennsilvaniano/Permiano da Bacia do Paraná foram verificados nos afloramentos da região de Lapa: Densipollenites Bharadwaj 1962 e Spackmanites Habib 1966. 0 primeiro constitui gênero de grão de pólen monossacado, conhecido em estratos pennsilvanianos (di Pasquo, 1999) e permianos (Bharadwaj, 1962; Stephenson, 2008) do Gondwana. Já o gênero de esporo Spackmanites parece ser restrito a estratos pennsilvanianos euroamericanos (Habib, 1966; Ravn, 1986; McLean et al., 2013). Contudo, nenhum aprofundamento taxonômico foi possível principalmente em razão de tratar-se de apenas um espécime de cada um destes táxons.

\subsection{Palinomorfos retrabalhados}

Em algumas das amostras, palinomorfos retrabalhados são muito comuns, de idades do Eoao Neodevonianas. Estes elementos, de preservação variável, são constituídos principalmente por prasinofíceas e acritarcos dos gênero Navifusa, Micrhystidium, Veryhachium, Triangulina e Gorgonisphaeridium. Dentre os palinomorfos retrabalhados com significado bioestratigráfico ocorre predomínio de espécies com idades do Meso ao Neodevoniano (Neo-ensiano - início do Neofrasniano), comumente encontradas no Membro São Domingos da Formação Ponta Grossa. Esse grupo inclui esporos pseudosacados (Grandispora), além de Leiotriletes balapucensis, acritarcos (Estiastra rhytidoa, Evittia sommer) e prasinofíceas (Duvernaisphaera angelae, Pterospermella crassimarginata, Hemiruptia legaultii e Maranhites spp). De forma subordinada ocorrem espécies comuns do Eo- ao Mesodevoniano, como esporos (Dictyotriletes emsiensis, Brochotriletes foveolatus, Synorisporites papillensis, Gneudaspora divelomedia e Tetraedraletes medinensis) e acritarcos (Multicisphaeridia ampliatum, Evitia remota). Algumas espécies de esporos, como Retusotriletes crassus e Lophozonotriletes sp. cf. L. dentatus, encontradas respectivamente nos afloramentos LP1 e PA2, são comumente registradas em associações do Neo- devoniano ao Mississipiano. A distribuição destes táxons ao longo dos níveis amostrados pode ser consultada em Kipper (2014).

A constatação de esporos, acritarcos ou cistos de prasinofíceas retrabalhados da seção devoniana já foi comprovada em diversos níveis estratigráficos do Grupo Itararé, tanto em seções aflorantes quanto em subsuperfície (e.g., Souza \& Petri, 1998; di Pasquo et al., 2003; Souza et al., 2000, 2010). Segundo Daemon \& Quadros (1970) e Souza (2006) trata-se de uma feição muito comum nas associações das camadas mais basais do Grupo Itararé. Em todos esses trabalhos anteriores, palinomorfos considerados indígenas foram reconhecidos mais abundantemente, facilitando a identificação da assembleia retrabalhada, cujas espécies têm amplitudes distintas e relativas a rochas devonianas e mississipianas. Contudo, as associações aqui estudadas apresentam uma situação oposta, sendo os táxons retrabalhados muito mais comuns quando comparados aos escassos registros de táxons pennsilvanianos.

Dois outros registros de associações palinológicas ricas em palinomorfos devonianos recuperadas em diamictitos são conhecidos no Estado do Paraná. Pires et al. (1992) identificaram acritarcos e cistos de prasinofíceas de idades devonianas (Ensiano ao Frasniano) em uma amostra coletada na BR 376, logo após a ponte sobre o Rio Tibagi, interpretada como registro glacial devoniano. Em subsuperfície (poço 2-0-1-PR, testemunho 14, a 953-954,4 $\mathrm{m}$ de profundidade), Loboziak et al. (1995) constataram situação semelhante em um diamictito, o qual foi posteriormente denominado como "Diamictito Ortigueira" por Milani et al. (2007), cuja associação é correspondente à Zona Retispora lepidophyta - Vallatisporites vallatus de Melo \& Loboziak (2003).

Em todas as três áreas estudadas no presente trabalho, foram verificadas ocorrências de espécies de prasinofíceas designadas como Leiosphaeridia spp. e Tasmanites spp., e de clorofíceas atribuídas a Quadrisporites spp. Contudo, considerando (i) que a distribuição estratigráfica destes gêneros é longeva, incluindo estratos paleozoicos mais antigos e (ii) que há vários táxons seguramente retrabalhados de idades devonianas associados, qualquer interpretação bioestratigráfica e/ou paleoambiental com base nestes registros pode ser comprometida. O estado de preservação e a cor destes espécimes não são critérios de diferenciação entre táxons indígenas e retrabalhados, uma vez que em ambas as situações, os espécimes tem ampla variação destas feições. Por outro lado, as formas atribuídas a Tasmanites spp. neste trabalho (Fig. 5R) são com- 
paráveis com outras também designadas sob mesma denominação por Daemon \& Quadros (1970) e Quadros (2002), consideradas indígenas no Grupo Itararé. Em França et al. (1996), a ocorrência de Tasmanites spp. em níveis estratigraficamente equivalentes aos aqui estudados foi utilizada para confirmar a influência marinha no ambiente de sedimentação da Formação Lagoa Azul na área.

Espécimes atribuídos a Botryococcus braunii têm presença rara no material estudado. Considerando que tais formas aquáticas continentais podem ser carreadas para ambientes salinos, onde apresentam certa tolerância, sua utilização para fins paleoambientais torna-se, neste caso, limitada.

\subsection{Análise integrada}

De modo geral, as associações palinológicas indígenas das três regiões são muito similares, com raros esporos e grãos de pólen monossacados e ausência de grãos de pólen bissacados, estriados ou poliplicados. Estes últimos palinomorfos são mais abundantes desde o topo do Grupo Itararé (Formação Taciba) até a Formação Rio do Rasto, equivalentes às zonas Vittatina costabilis e Lueckisporites virkkiae. A presença de espécies retrabalhadas pré-Pennsilvanianas é também uma das características das duas unidades inferiores do Grupo Itararé, formações Lagoa Azul e Campo Mourão, sendo mais comuns na primeira (Daemon \& Quadros, 1970; Souza \& Petri, 1998; Souza, 2006), mas também constatados em níveis atribuídos à Zona Crucisaccites monoletus (Souza et al., 2000, 2010; di Pasquo et al., 2003), litoestratigraficamente correspondente à última formação ( Holz et al., 2010). Estas características foram observadas na análise comparativa das três regiões estudadas. Nos depósitos mais basais, da região de Porto Amazonas, raros grãos de pólen monossacados foram registrados (Cannanoropolis, Caheniassacites e Potoniesporites), em conjunto com uma grande abundância e diversidade de espécies retrabalhadas. Por outro lado, nos afloramentos localizados na porção central e sul da área (Lapa e Campo do Tenente) ocorre um incremento relativo de grãos de pólen monossacados (Cannanoropollis, Caheniasaccites, Circumplicatipollis, Costatascyclus, Crucisaccites Densipollenites, Potonieisporites) e uma diminuição na frequência das espécies retrabalhadas, principalmente acritarcos.

A variação quantitativa e qualitativa no padrão de distribuição dos palinomorfos indígenas, bem como na participação de táxons retrabalhados, podem ser reflexos das condições paleoclimá- ticas e deposicionais. Os estratos de Porto Amazonas, com poucos registros de espécies indígenas, indicam um período de condições frias, não favoráveis ao desenvolvimento da cobertura vegetacional adjacente ao sítio deposicional. A abundância de palinomorfos retrabalhados pode ser resultado da proximidade da área fonte e das condições deposicionais, caracterizadas por diamictitos deformados (fácies Dmm-d) gerados por fluxos gravitacionais de massa, que incorporam e ressedimentam fragmentos de depósitos preexistentes, em um ambiente de talude subaquoso. Como consequência, estes podem, em termos quantitativos, mascarar a presença de elementos indígenas, dificultando a interpretação bioestratigráfica.

Por outro lado, em Lapa e Campo do Tenente, há o predomínio de ritmitos (RFS, RSF, RSFo) e folhelhos (Fl) com baixo conteúdo de clastos, resultantes de correntes de turbidez de baixa densidade, o que representa um período de retração glacial, refletindo condições mais favoráveis para o desenvolvimento de vegetação, com maior participação no conteúdo de palinomorfos indígenas.

\section{Conclusões}

A análise palinológica deste estudo permitiu o reconhecimento de nove espécies de esporos e 12 espécies de grãos de pólen indígenas para a Formação Lagoa Azul nos afloramentos de Porto Amazonas, Lapa e Campo do Tenente, sudeste do Estado do Paraná, incluindo dois táxons inéditos para o intervalo Pennsilvaniano/Permiano da Bacia do Paraná: Densipollenites Bharadwaj 1962 e Spackmanites Habib 1966. Além disso, também foram registrados espécimes designados taxonomicamente de forma aberta como "grãos de pólen monossacados" e como representantes microplanctônicos.

O predomínio de grãos de pólen monossacados, assim como a presença de Cristatisporites menendezii e Costatascyclus crenatus, espécies exclusivas da Zona Ahrensisporites cristatus (ZAc), somado com a ausência de elementos típicos das biozonas suprajacentes, ZCm e ZVc, permitem posicionar o intervalo de estudo na ZAc. Isto implica uma idade incluída no intervalo Neobashkiriano ao Kasimoviano e uma correlação bioestratigráfica da seção de estudo da Formação Lagoa Azul com a porção inferior do Grupo Itararé (Souza, 2006; Holz et al., 2010). Contudo, a constatação de Costatascyclus crenatus na Formação Aquidauana no Estado do Mato Grosso do Sul por Souza et al. (2015), com associação característica da ZCm requer reanálise do zoneamento de Souza (2006), ainda que 
esta zona tenha sido proposta para o Grupo Itararé nos estados de São Paulo e Paraná, o que poderia refletir em distintas distribuições das espécies guias em áreas fora desta abrangência.

Os elementos microplanctônicos atribuídos à Tasmanites spp. e Leiosphaeridia spp. (Prasinophyceae) são, em parte, considerados indígenas devido à semelhança com formas consideradas coevas do Grupo Itararé, apresentadas em trabalhos anteriores (Daemon \& Quadros, 1970; Quadros, 2002). Assim, estes elementos confirmariam a natureza marinha ou de influência marinha nos níveis onde ocorrem, embora não se descarte a possibilidade de uma parcela destes táxons ser retrabalhada, devido à sua abundância na Formação Ponta Grossa.

Os palinomorfos retrabalhados são constituídos principalmente por prasinofíceas e acritarcos do gênero Navifusa, Micrhystidium, Veryhachium, Triangulina e Gorgonisphaeridium, com longa amplitude estratigráfica. Dentre os táxons com significado bioestratigráfico ocorre um predomínio de espécies com idades do Meso- ao Neodevoniano; de forma subordinada ocorrem palinomorfos com idade entre o Eo- ao Mesodevoniano. A presença rara de esporos comuns em intervalos do Neodevoniano ao Mississipiano também sugere uma provável proveniência desta idade.

A abundância de palinomorfos retrabalhados pode ser resultado da proximidade da área fonte pré-pennsilvanianas e das condições deposicionais, caracterizadas predominantemente por fluxos gravitacionais de massa, em um ambiente subaquático glacio-influenciados que, quando avançam, incorporam e ressedimentam fragmentos de estratos preexistentes. Comparativamente a outras associações da base do Grupo Itararé, os afloramentos de Porto Amazonas comportam os níveis com maior ocorrência de espécies retrabalhadas da unidade relatadas até o momento. Nestes níveis, são registrados poucas espécies indígenas, o que pode ser também o resultado de condições climáticas mais frias, não favoráveis ao desenvolvimento de vegetação. Por outro lado, as associações de Lapa e Campo do Tenente, considerados os níveis mais jovens, apresentam um incremento no conteúdo de palinomorfos indígenas, principalmente grãos de pólen monossacados, refletindo condições climáticas mais favoráveis para o desenvolvimento de vegetação.

Os resultados palinológicos dos níveis estudados confirmam a ocorrência da Formação Lagoa Azul em superfície pelo menos até o município de Campo do Tenente, no sul do Paraná. Corroboram, desta forma, conclusões de autores prévios (vide
França et al, 1996; Vesely et al., 2015) que consideraram a hipótese de onlap desta unidade para sul.

Agradecimentos. Este trabalho faz parte da Dissertação de Mestrado do primeiro autor junto ao Programa de Pós-graduação em Geologia da Universidade Federal do Paraná. Os autores agradecem à Cristina Moreira Félix e Cristina Silveira Vega pelas sugestões apresentadas ao longo dos trabalhos de coleta e identificação taxonômica; ao Bruno Tubino Noronha, pelo auxílio no processamento laboratorial; ao CNPq pelos recursos por meio de projetos de pesquisa (Processos 401769/20100, 461628/2014-7, 310727/2014-6).

\section{Referências}

Azcuy, C., Beri, A., Bernardes-de-Oliveira, M.E.C., Carrizo, H.A., di Pasquo, M., Díaz Saravia, P., González, C., Iannuzzi, R., Lemos, V.B., Melo, J.H.G., Pagani, A., Rohn, R., R. Amenábar, C., Sabattini, N., Souza, P.A., Taboada, A. \& Vergel, M. del M. 2007 Bioestratigrafía del Paleozoico Superior de América del Sur: primera etapa de trabajo hacia uma nueva propuesta cronoestratigráfica. Asociación Geológica Argentina, Serie D: Publicación Especial n ${ }^{\text {o. }} 11,64 p$.

Azcuy, C.L. 1975a. Miosporas del Namuriano y Westfaliano de la Comarca Malazán-Loma Larga, Província de La Rioja, Argentina. II. Localización geográfica y geológica de la comarca y descripciones sistemáticas. Ameghiniana, XII(1): 1-69.

Azcuy, C.L. 1975b. Miosporas del Namuriano y Westfaliano de la Comarca Malazán-Loma Larga, Província de La Rioja, Argentina. II. Descripciones sistemáticas y significado estratigráfico de las microfloras. Ameghiniana, XII(2): 113-163.

Bharadwaj, D.C. 1962. The miospore genera in the coals of Raniganj Stage (Upper Permian), India. The Palaeobotanist, 9(1/2): 68-106 (1960).

Bouma, A.H. 1962. Sedimentology of Some Flysch Deposits: a graphic approach offacies interpretation. Amsterdam, Elsevier, 167p.

Césari, S.N. \& Gutiérrez, P.R. 2000. Palynostratigraphy of Upper Paleozoic sequences in central-western Argentina. Palynology, 24: 113-146.

Daemon, R.F. \& Quadros LP. 1970. Bioestratigrafia do Neopaleozóico da Bacia do Paraná. In: CONGRESSO BRASILEIRO DE GEOLOGIA, 24, 1970, Brasília, Anais... SBG, Brasília, p. 359-412.

di Pasquo, M.M. 1999. Palinologia, bioestratigrafia y correlacion de las associaciones presentes en los Grupos Machareti y Mandiyuti, Neopaleozoico de Argentina. Buenos Aires, 480p. Tese de Doutorado, Facultad de Ciéncias Exactas y Naturales, Universidade de Buenos Aires.

di Pasquo, M.M., Azcuy, C.L. \& Souza, P.A. 2003. Palinología del Carbonífero Superior del Subgrupo Itararé en Itaporanga, Cuenca Paraná, Estado de São Paulo, Brasil. Parte 2: sistemática de polen y significado paleoambiental y estratigráfico. Ameghiniana, 40(3): 297-313. 
Eyles, C.H., Eyles, N. \& Miall, A.D. 1985. Models of glaciomarine sedimentation and their application to the interpretation of ancient glacial sequences. Palaeogeography, Palaeoclimatology, Palaeoecology, 51: 15-84.

Eyles, N., Eyles, C.H. \& França, A.B. 1993. Glaciation and tectonics in an active intracratonic basin: The Late Paleozoic Itararé Group, Paraná Basin, Brazil. Sedimentology, 40: 1-25.

Félix, C.M. 2007. Palinotaxonomia e bioestratigrafia de gêneros de grãos de pólen monossacados selecionados da Bacia do Paraná, Brasil. Porto Alegre, 119p. Dissertação de Mestrado, Programa de Pós-graduação em Geociências, Instituto de Geociências, Universidade Federal do Rio Grande do Sul.

Félix, C.M. \& Souza, P.A. 2008. Análise palinotaxonômica e bioestratigráfica da Subturma Monosaccites na Bacia do Paraná, Brasil. II: Gêneros Costatascyclus, Circumplicatipollis, Caheniasaccites, Stellapollenites e Divarisaccus. Pesquisas em Geociências, 35(2): 57 69.

Fielding, C.R., Frank, T.D. \& Isbell. J.L. 2008. The Late Paleozoic Ice Age - A review of current understanding and synthesis of global climate patterns. In: C.R. Fielding, T.D. Frank \& J.L. Isbell (Eds.), Resolving the Late Paleozoic Ice Age in Time and Space. Geological Society of America Special Publication 441, p. 343354.

Frakes, L.A. \& Crowell, J.C. 1967. Facies and paleogeography of late Paleozoic Lafonian diamictite, Falkland Islands. Geological Society of America Bulletin, 78: 37-58.

Frakes, L.A. \& Crowell, J.C. 1969. Late Paleozoic glaciation: I, South America. Geological Society of America Bulletin, 80: 1007-1042.

França, A.B. \& Potter, P.E. 1988. Estratigrafia, ambiente deposicional e análise de reservatórios do Grupo Itararé (Permocarbonífero), Bacia do Paraná (Parte I). Boletim de Geociências da Petrobrás, 2: 147-191.

França, A.B., Winter, W.R. \& Assine, M.L. 1996. Arenitos Lapa-Vila Velha: um modelo de trato de sistemas subaquosos canal-lobos sob influência glacial, Grupo Itararé (C-P), Bacia do Paraná. Revista Brasileira de Geociências, 26: 43-56.

Habib, D. 1966. Distribution of spore and pollen assemblages in the Lower Kittanning Coal of Western Pennsylvania. Palaeontology, 9(4): 629- 666.

Holz, M., França, A.B., Souza, P.A., Iannuzzi, R. \& Rohn, R. 2010. A stratigraphic chart of the Late Carboniferous/Permian succession of the eastern border of the Paraná Basin, Brazil, South America. Journal of South American Earth Sciences, 29: 381-399.

Isbell, J.L., Miller, M.F., Wolfe, K.L. \& Lenaker, P.A. 2003a. Timing of late Paleozoic glaciation in Gondwana: Was glaciation responsible for the development of northern hemisphere cyclothems? In: Chan, M.A. \& Archer, A.A. (Eds.), Extreme Depositional Environments: Mega End Members in Geologic Time. Geological Society of America 370 (Special Papers), p. 5-24.

Isbell, J.L., Lenaker, P.A., Askin, R.A., Miller, M.F. \& Babcock, L.E. 2003b. Reevaluation of the timing and ex- tent of late Paleozoic glaciation in Gondwana: Role of Transantarctic Mountains. Geology, 31: 977-980.

Kipper, F. 2014. Palinoestratigrafia da porção inferior do Grupo Itararé (Carbonífero) no sudeste do estado do Paraná. Curitiba, 126p. Dissertação de Mestrado, Programa de Pós-graduação em Geologia, Departamento de Geologia, Universidade Federal do Paraná.

Limarino, C.O., Tripaldi, A., Marenssi, S. \& Fauqué, L. 2006. Tectonic, sea-level, and climatic controls on Late Paleozoic sedimentation in the western basins of Argentina. Journal of South American Earth Sciences, 22: 205-226.

Loboziak, S., Melo, J.H.S., Steemans, P. \& Barrilari, I.M.R. 1995. Miospores evidence for pre-Emsian and latest Famennian sedimentation in the Devonian of the Paraná basin, south Brazil. Anais da Academia Brasileira de Ciências, 67(3): 391-392.

López Gamundí, O.R. 1997. Glacial-postglacial transition in the Late Paleozoic basins of southern South America. In: Martini, I.P. (Ed.), Late Glacial and Postglacial Environmental Changes-Quaternary, Carboniferous-Permian, and Proterozoic. New York, Oxford University Press, p. 147-168.

Maack, R.A. 1946. Geologia e geografia da região de Vila Velha (Paraná) e considerações sobre a glaciação carbonífera no Brasil. Arquivos do Museu Paranaense, 5: 1-305. 1946.

Marques-Toigo, M. 1988. Palinologia, bioestratigrafia e paleoecologia do Neopaleozóico da Bacia do Paraná nos estados do Rio Grande do Sul e Santa Catarina, Brasil. Porto Alegre, 259p. Tese de Doutoramento, Programa de Pós-graduação em Geociências, Instituto de Geociências, Universidade Federal do Rio Grande do Sul.

Marques-Toigo, M. 1991. Palynobiostratigraphy of the southern Brazilian Neopaleozoic Gondwana sequence. In: Ulbrich, H.E. \& Rocha Campos, A.C. (Eds.), $7^{\text {st }}$ International Gondwana Symposium, São Paulo, Brasil, Proceedings, p. 503-515.

McLean, D., Owens, B., Pendleton, J.L. \& Bodman, D. 2013. Pennsylvanian (Namurian and Westphalian) miospore assemblages from the west coast of Scotland. Review of Palaeobotany and Palynology, 190: $1-14$.

Melo, J.H.G. \& Loboziak, S. 2003. Devonian-Early Carboniferous miospore biostratigraphy of the Amazon Basin, Northern Brazil. Review of Palaeobotany and Palynology, 124: 131-202.

Miall, A.D. 1978. Lithofacies types and vertical profile models of braided river deposits, a summary. In: Miall, A.D. (Ed.), Fluvial Sedimentology. Canadian Society of Petroleum Geologists Memoir 5, p. 597-604.

Miall, A.D. 1996. The Geology of Fluvial Deposits Sedimentary Facies, Basin Analysis, and Petroleum Geology. Berlin, Springer, 582 p.

Milani, E.J. 1997. Evolução tectono-estratigráfica da bacia do Paraná e seu relacionamento com a geodinâmica fanerozóica do Gondwana sul-oriental. Porto Alegre, 255p. Tese de Doutoramento, Programa de Pós-graduação em Geociências, Instituto de Geociências, Universidade Federal do Rio Grande do Sul. 
Milani, E.J., Melo, J.H.G., Souza, P.A., Fernandes, L.A. \& França, A.B. Bacia do Paraná. 2007. Boletim de Geociências da Petrobrás, 15(2): 265-287.

MINEROPAR. Minerais do Paraná S.A. 2007. Mapa geológico do Estado do Paraná, Folha de Ponta Grossa. SG.22-X-C-II. Curitiba, mapa geológico, escala 1:100.000.

Pires, F.A., Oliveira, S.F., Burjack, M.I.A. \& Petri, S. 1992. A glaciação devoniana na Bacia do Paraná: dados paleontológicos. In: CONGRESSO BRASILEIRO DE GEOLOGIA, 37, 1992, São Paulo. Boletim de Resumos Expandidos... São Paulo, SBP, p. 533-534.

Quadros, L.P. 2002. Acritarcos e Tasmanites do Permo-Carbonífero da Bacia do Paraná. Revista do Instituto Geológico, 23: 39-50.

Quadros, L.P. \& Melo, J.H.G. 1987. Método prático de preparação palinológica em sedimentos Pré-Mesozóicos. Boletim de Geociências da Petrobrás, 1: 205214.

Ravn, R.L. 1986. Palynostratigraphy of the Lower and Middle Pennsylvanian of Iowa. Iowa Geological Survey Technical Paper, 7: 1-245.

Rocha-Campos, A.C., Basei, M.A.S., Nutman, A.P \& Santos, P. 2006. Shrimp U-Pb zircon geochronological calibration of the Late Paleozoic Supersequence, Paraná Basin, Brazil. In: SOUTH AMERICAN SYMPOSIUM ON ISOTOPIC GEOLOGY, 5, 2006, Punta del Este, Uruguay. Short papers, p. 298-301.

Schneider, R. L., Muhlmann, H., Tommasi, E., Medeiros, A., Daemon, R.F. \& Nogueira, A.A. 1974. Revisão estratigráfica da Bacia do Paraná. In: CONGRESSO BRASILEIRO DE GEOLOGIA, 28, Porto Alegre. Anais... Porto Alegre: SBG, p. 41-65.

Souza, P.A. 2006. Late Carboniferous palynostratigraphy of the Itararé Subgroup, northeastern Paraná Basin, Brazil. Review of Palaeobotany and Palynology, 38: 9-29.

Souza, P.A. \& Petri, S. 1998. Reworked palynomorphs in the Upper Carboniferous sediments at Araçoiaba da Serra (Itararé Subgroup, Paraná Basin), State of São Paulo, Brazil. Ameghiniana, 35(4): 379-385.

Manuscrito 595

Editoras: Marina Bento Soares \& Maria do Carmo Lima e Cunha.
Souza, P.A. \& Marques-Toigo, M. 2005. Progress on the palynostratigraphy of the Permian strata in Rio Grande do Sul State, Paraná Basin, Brazil. Anais da Academia Brasileira de Ciências, 77: 353-365.

Souza, P.A., Batezelli, C.V.B., di Pasquo, M., Azcuy, C.L., Saad, A.R. \& Perinotto, J.A.J. 2000. Ocorrência de palinomorfos no Subgrupo Itararé (C/P da Bacia do Paraná) em Jundiaí (SP, Brasil). Revista Universidade Guarulhos, Geociências no 5 (no esp.): 28-32.

Souza, P.A., Félix, C.M., Pérez-Aguilar, A. \& Petri, S. 2010. Pennsylvanian palynofloras from the Itu rhythmites (Itararé Subgroup, Paraná Basin) in São Paulo State, Brazil. Revue de Micropaléontologie, 53(2): 69-83.

Souza, P.A., Perinotto, J.A.J., Félix, C.M. \& Araújo, B.C. 2015. Biostratigraphy and paleoecology of an unusual palynological record from the Aquidauana Formation, Late Pennsylvanian of Paraná Basin. Anais da Academia Brasileira de Ciências, 87(2): 611-622.

Stephenson, M.H. 2008. Spores and pollen from the middle and upper Gharif members (Permian) of Oman. Palynology, 32: 157-182.

Suss, J.F., Vesely, F.F., Santa Catharina, A., Assine, M.L. \& Paim, P.S.G. 2014. O Grupo Itararé (Neocarbonífero-Eopermiano) entre Porto Amazonas (PR) e Mafra (SC): sedimentação gravitacional em contexto marinho deltaico sob influência glacial. Geociências, 33(4): 701-719.

Vesely, F.F. \& Assine, M.L. 2004. Seqüências e tratos de sistemas deposicionais do Grupo Itararé, norte do Estado do Paraná. Revista Brasileira de Geociências, 34: 219-230.

Vesely, F.F. \& Assine, M.L. 2014. Ice-keel scour marks in the geological record: evidence from Carboniferous soft-sediment striated surfaces in the Paraná Basin, southern Brazil. Journal of Sedimentary Research, 84: 26-39.

Vesely, F.F., Trzaskos, B., Kipper, F., Assine, M.L. \& Souza, P.A. 2015. Sedimentary record of a fluctuating ice margin from the Pennsylvanian of western Gondwana: Paraná Basin, southern Brazil. Sedimentary Geology, 326: 45-63. 
